\title{
The impact of donor CMV infection on kidney graft outcome
}

Cytomegalovirus (CMV) is the most common cause of viral infection in recipients of solid organ transplants. However, the impact of donor CMV infection on graft survival is not yet clear. Now, new data from a retrospective study suggest that donor CMV seropositivity increases the risk of kidney graft loss.

To investigate the impact of donor CMV infection on graft survival and identify factors that modulate the risk of graft loss, Philippe Gatault and colleagues analysed

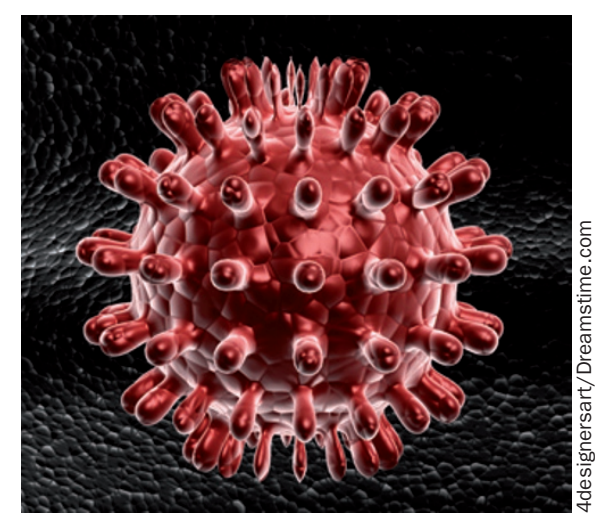

long-term graft survival, CMV serology, pp65 antigenaemia status (a measure of CMV viraemia) and $\mathrm{CD}^{+} \mathrm{T}$-cell populations in 1,279 kidney transplant recipients. They found that positive CMV serology-but not antigenaemia-in the donor was an independent risk factor for graft loss. Grafts from CMVpositive donors were associated with poor outcomes even in antigenaemia-free recipients. "The impact of donor CMV serostatus on graft survival was greatest in CMV-seropositive recipients (that is, those who were infected with the virus before transplantation), suggesting that these patients have a poor ability to control CMV infection in the graft," says Gatault.

The researchers report that the negative impact of donor CMV seropositivity on graft survival was limited to fully HLA class I-mismatched recipients. They suggest that this mismatch could have a detrimental effect on the ability of the recipient's $\mathrm{CD} 8^{+} \mathrm{T}$ cells to control intragraft $\mathrm{CMV}$ replication. At 2 years after transplantation, $\mathrm{CD} 8^{+} \mathrm{T}$-cell counts were increased in $\mathrm{CMV}$-seronegative but not in $\mathrm{CMV}$-seropositive recipients of kidneys from CMV-seropositive donors. Moreover, a reduction in CD8 ${ }^{+} \mathrm{T}$-cell counts of $40 \%$ or more was associated with a significant reduction in graft survival in CMV-seropositive recipients exposed to CMV.

"Our findings suggest that CMV infection in the graft contributes to chronic graft dysfunction and that the usual monitoring for viraemia does not predict this risk," concludes Gatault. "Further research to identify predictive biomarkers seems essential." He suggests that allocation of grafts from CMVseropositive donors to $\mathrm{CMV}$-seropositive recipients could be avoided in order to prevent $\mathrm{CMV}$-associated chronic allograft dysfunction.

\section{Ellen F. Carney}

Original article Gatault, P. et al. CMV infection in the donor and increased kidney graft loss: impact of full HLA-I mismatch and posttransplantation $\mathrm{CD}^{+}$cell reduction. Am. J. Transplant. doi:10.1002/ajt.12298 